\title{
20
}

\section{From Protest to Taskforce}

\author{
Dinah Murray
}

The National Autistic Taskforce's (NAT) main focus is on autonomy and justice for people who don't use speech to meet their needs; that was also the main focus of the APANA story, and that is where the next stage of this narrative starts, as one of its key players is Virginia Bovell who was on the parliamentary advisory group that learnt about neuroleptics from Wen Lawson and myself. This section is about how the NAT came to be and what lessons can be learnt.

\section{Autistic Influence on the Emergence of Autistica}

At that All-Party Parliamentary Group on Autism (APPGA) meeting mentioned above, and after it, my concession that in some cases at low doses

D. Murray $(\varangle)$

London, UK 
some people find risperidone helpful was clearly a vital step towards credibility (though not liked by the APANA parents at the time). Virginia, founder of an applied behavioral analysis (ABA) school and achiever of British version nicey-nice $\mathrm{ABA}$, was also concerned about eugenics, so a while later we met again to talk about that and I met her son Danny. Some years passed, then one day in 2008 she and I did a double take in the street and she asked me in for a cuppa (tea). We had a very pleasant chat and exchanged phone numbers. Despite our very different views of behaviourism, we had much common ground.

Just a week later I got a very disturbed phone call from Virginia. A new CEO of her school (Treehouse), unaware of their bad name had invited Bob Wright, founder of Autism Speaks, to launch a new series of annual lectures on autism. To many people it was already clear how distorted their deeply medical model of autism was, with its analogy to cancer as a problem to be wiped out as soon as possible, including by genetic intervention. So Treehouse needed help and we built on our common ground despite a difference of view that could have ruled that out.

The solution I proposed was to: establish a creative autistic presence; give autistic people a chance to say what people most need to hear about autism; have the widest possible exposure; rebalance the specific event to diminish Autism Speaks' impact. This created alliances and generated obligations. Treehouse gave me funding for a professional editor, for two-minute videos from the Autistic Self Advocacy Network (ASAN), members of my Posautive Youtube group, and Autscape (see Buckle, Chapter 8) members as well as from personal contacts. Two thousand Something About Us DVDs (Something About Us [1] were made and distributed-free and copyrightfree (now part of the exhibition at RightfulLives, www.rightfullives.net/ Community-of-Perspectives.html). At the event in London's City Hall, everyone including the visiting Wrights was asked to flap not clap. An autistic woman, Anya Ustaswewski, cogently responded, and an audience with many invited autistic people (see the videos at RightfulLives). There was a small demo outside with these signs (see Figs. 20.1 and 20.2).

Another result was that people were indebted to the autistic input and Virginia introduced me to key people who recognized the debt (I was not paid myself). Those included Hilary Gilfoy of whom more below. 


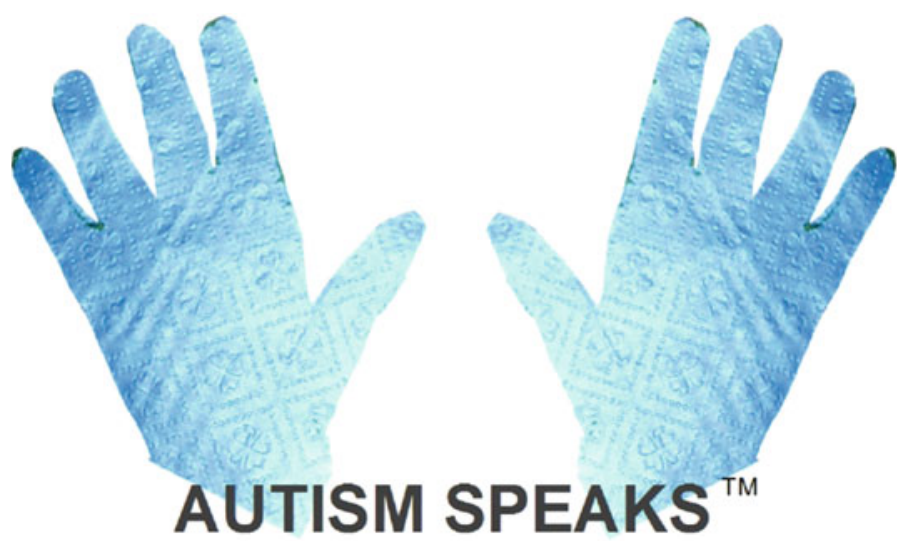

It's time to resist them.

Fig. 20.1 Anti-Autism Speaks Logo designed by Dinah Murray

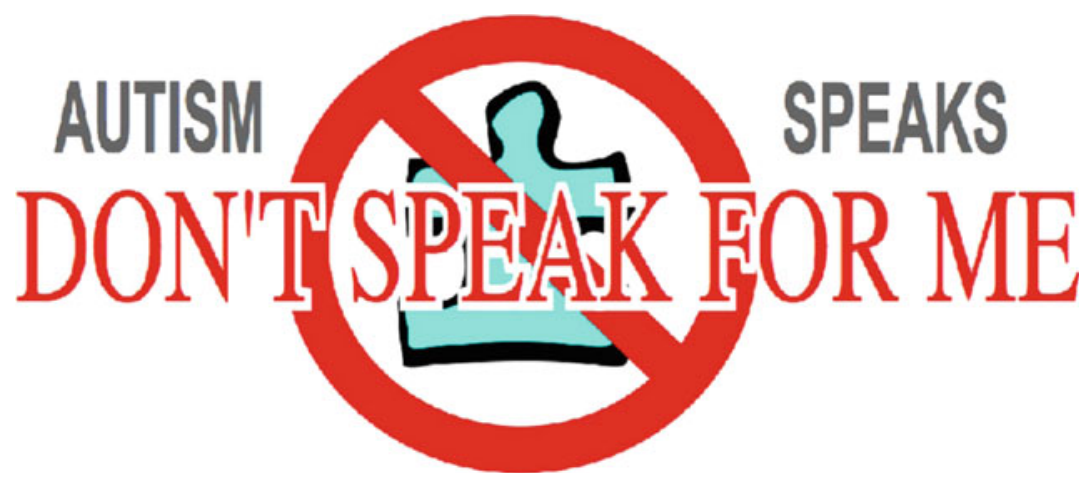

Fig. 20.2 Another Anti-Autism Speaks Logo circulating in 2008, anonymous

This event strengthened my standing as a reasonable person (not all may agree) again because I had conceded some ground myself, i.e. that the UK behaviorists were not themselves devil's spawn. The whole ghastly visitperhaps with a bit of help from our well-found critique - contributed to a painful and difficult process as the UK organization that had been paired with the US Autism Speaks severed the partnership and reinvented itself as the strictly British Autistica (which now has a Director of Science who is autistic himself). I kept up good relations with Hilary Gilfoy in person 
over the next years as she seemed to me a fair-minded person who was going to some lengths to distance and separate her organization-funded by Dame Stephanie (Steve) Shirley in the UK-from the Americans.

\section{Autistic Input into the National Autism Project}

A few more years passed and in 2014, Dame Steve, who had used her unexpected great wealth (see her autobiography, Let It Go [2]) to give very many millions of pounds toward fathoming what autism is all about, decided to commission the "National Autism Project" (NAP) to study whether anything useful had emerged from all these decades of autism practice and research, much of it funded by her.

Thus, in 2015 Ian Ragan and Elizabeth Vallance (from the original Autism Speaks UK) approached me to join the NAP Strategy Board. I felt honored, but it mattered to me that if I said yes I wouldn't just be there as "window dressing." As I explained, my experience as a trophy autistic person at the National Autistic Society had been recent and bruising. I also did some agonizing over the generous benefactor's past involvement with Autism Speaks and her own attitude to autism; but she had funded the first online autism conference, in 1999, to which I'd contributed with Mike Lesser and the Webautism course which I helped develop and taught on at Birmingham University - and Autistica was being transformed. Also, they agreed to everything I asked for.

I asked for: communication support for attending Board meetings (in the shape of Damian Milton), as I knew my ability to speak up in a timely manner was limited at best; I was also concerned that I needed my own 'sounding board' and input from beyond my own limited perspective. Happily both these ideas were accepted and I constructed a strong advisory panel with a wide range of both academic and practical knowhow, and I was able to come to Strategy Board meetings with the unfailingly articulate (and like-minded) Damian. Hilary Gilfoy, who had guided Autistica's disentanglement from Autism Speaks, was not technically on the Board, but took excellent minutes at Board meetings and was perceived as a 
supportive presence by both Damian and myself (and, I think, by her old friend Dame Steve) owing to her calm friendliness.

Having someone as steady as Damian by my side, who also had a fantastic grasp of all the key issues, transformed my capacity to be of some use at the meetings. Eventually everyone was treating us both as equal Board members, and he was contributing freely on the spot in a way I cannot perform myself. There were few occasions when our views diverged, which obviously helped - and at the final Board meeting Damian couldn't attend and I managed to contribute quite fluently myself as I had learnt to trust the people there. How did that happen?

It didn't start too well. A lot of work had been done and decisions taken before the first Board meeting took place - that included drawing up a list of Experts, all of them professionals from academics to psychiatrists to charity bods. I queried why the Autistic Advisory Panel (AAP), who I knew to be deeply knowledgeable in the field, did not also count as "experts." I went and met and talked to the report researchers Professor Knapp and postgraduate Valentina Iemmi quite early on, and I think opened their eyes to how much disability can be created by a hostile environment and what that might mean vis-à-vis autism. They appeared genuinely interested. Even so, by the summer of 2015 I was beginning to think of resigning because of the way the AAP members were lumped together as "Dinah's panel" and their individual great expertise disregarded. However, Damian, AAP member Catriona Stewart, and I had a chat at Autscape and Catriona argued for the Panel to have a face-to-face meeting, which we later did, with the NAP Project Leader, the NAP Chair, and Hilary in attendance. That was the beginning of the real listening.

Gradually all the people on the Panel became distinct and valued contributors to the NAP. The interesting and open-minded other members of the Strategy Board began to hear favorable things about us. Two of the AAP members were turned from pawns to queens and added to the Experts list-Drs Yo Dunn and Catriona Stewart. Cat was their Scottish specialist and Yo was far the most effective and knowledgeable expert they had when it came to calling the Government out on its own laws. In effect she became the NAP's warhead, wheeled into many discussions with senior civil servants to blow them away with her detailed and accurate legal knowledge. 
By the time the Project report, The Autism Dividend, was launched in early 2017, the large contribution of members of the Panel as well as our "experts" was being explicitly recognized. The report was repeatedly revised and improved by our critical input — and saved from some serious failings - which resulted in Damian and myself being honored at the report launch in a House of Lords venue, as "Productive Irritants" by its lead author, Martin Knapp. Some fundamental differences from his earlier report on "the cost of autism" were that the burden/disease concept had been replaced by explicit recognition of autistic potential and of the varied barriers that prevent it from being realized; it also highlighted a very poor evidence base for most practice, resulting from widespread very low research standards (see autistic researcher Michelle Dawson on Twitter, @autismcrisis, for much more about those).

At that year's Autscape (see Buckle, Chapter 8), five members of the AAP were there, and the National Autism Project's willingness to listen and take us seriously was feted and rejoiced in: the final report is much admired. We are all proud to have contributed to its excellence. Widely seen as the highlight of the 2017 Autscape, Yo Dunn gave a stunning, passionate talk about what she called "The Other Half" and what is more fluent autistic people can and should do about the vast numbers of autistic people who are not articulate but depend on frequent or full-time support. Privately we discussed the idea that if some sort of future for the AAP was going to emerge, its point could be to focus on the Other Half.

In parallel with these discussions, unknown to us, Dame Steve was having some thoughts of her own. Those led her to entrust me with the generous sum of $£ 100,000$ to fund a continuation and transformation of the NAP's AAP. She was clearly pleased we chose to focus on people, like her late son, Giles, who need the most communication support. The new body was named the NAT and acquired the strapline: Bolder VoicesBetter Practice.

\section{The National Autistic Taskforce}

With Damian Milton as project leader, we conceived the Taskforce's main practical aim to be to turn more of the promises encoded in weak and 
toothless legislation into realities, for people who are poorly placed even to recognize let alone defend their own rights and interests and whose parents are often cut out of discussions when their offspring are teenagers.

We are identifying specific targets and crucial steps along the way, as well as potential obstacles and ways to get around them. We have small focused working groups (GNATs, or Groups of the NAT) on changing practice in the target areas. We are also building up a wider network of autistic individuals and groups across the British Isles so we can draw on a wide range of expertise with as broad and well-informed views as possible. Thanks to this terrific bunch of committed and knowledgeable people, we have been already able to interact constructively with agents of government and other stakeholders, and thanks to Yo Dunn in particular, the Taskforce has drafted several well-supported and closely argued responses to relevant government consultations on behalf of NAT (see nationalautistictaskforce. org) and created the NAT Independent Guide [3].

We think we are well-placed to be seen as carrying some weight, with an executive made up of Kabie Brook, Leneh Buckle, Yo Dunn, and Damian Milton as project leader; and the NAT's history and status mean we have some enviable introductions and contacts. We think our connection with the National Autism Project means that, from an establishment position, we are seen from the start as both credible and significant. Big charities that say they are speaking for autistic people always have their own survival as top priority.

\section{Lessons Learned}

What lessons can we learn from this narrative, stretching from the mid90s to the present day? The process involved creating, discovering, and using community of interest-i.e. shared values and passions-among a diverse range of people whose interests and views outside our specific common purposes often differed widely. Working alongside other autistic people may take quite a lot of additional work (by all concerned) to ensure that communication is effective and perceptions of all sorts are factored in, allowed for and not seen as insuperable barriers, even if there's some 
potentially painful cognitive dissonance. That said, having autistic comrades along when entering any lions' dens can in my experience make all the difference between being able or not able to communicate effectively. Our impact partly depends on pragmatic adaptation, but our strongest suit is being people with the passion and commitment and indifference to hierarchy to persevere obstinately against the odds. Be an opportunity hound, don't miss a chance!

I have always made a point of assuming everyone has a good heart, as Kabie Brook of Autism Rights Group Highlands (ARGH) recently pointed out to me in relation to the NAT - only once or twice has this precept let me down. In every campaign I found that goodwill, fellow feeling, and knowhow were freely shared, and personal connections were crucial. Expecting and also returning tolerance, understanding, and acceptance from others has worked well to further aims. I found it's best to expect mistakes, delays, miscommunications, so as not be "thrown" by these: they are inevitable and it is usually pointless or harmful to attach blame (of self or others) to any of them. If at all possible, stay polite, work on the common ground and remember that though changing practices and attitudes can take decades, lots of small changes really can add up to big ones.

On a more cynical note, remember that when reputations are at stake the power imbalance shifts if those with least power have a voice that can be heard. That's why digital inclusion is so vital and a strategic goal of the NAT. On we go.

\section{References}

1. Murray, D., \& Benstock, J. (2008). Something about us [Documentary].

2. Shirley, S., \& Askwith, R. (2012). Let it go: The memoirs of Dame Stephanie Shirley. UK: Andrews UK Limited.

3. National Autistic Taskforce (NAT). (2019). An independent guide to quality care for autistic people. https://nationalautistictaskforce.org.uk/wp-content/ uploads/RC791_NAT_Guide_to_Quality_Online.pdf. 
Open Access This chapter is licensed under the terms of the Creative Commons Attribution 4.0 International License (http://creativecommons.org/licenses/by/ $4.0 /$ ), which permits use, sharing, adaptation, distribution and reproduction in any medium or format, as long as you give appropriate credit to the original author(s) and the source, provide a link to the Creative Commons license and indicate if changes were made.

The images or other third party material in this chapter are included in the chapter's Creative Commons license, unless indicated otherwise in a credit line to the material. If material is not included in the chapter's Creative Commons license and your intended use is not permitted by statutory regulation or exceeds the permitted use, you will need to obtain permission directly from the copyright holder.

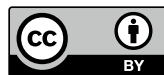

